\title{
The use of bronchial blockers in patients with aberrant tracheobronchial anatomy: a case report
}

\author{
Yanan Lu", Dongni Xu", Zhongqi Liu, Ting Liu, Jianfeng Zeng, Minghui Cao, Fengtao Ji \\ Department of Anesthesiology, Sun Yet-sen Memorial Hospital, Sun Yet-sen University, Guangzhou, China \\ "These authors contributed equally to this work. \\ Correspondence to: Fengtao Ji; Minghui Cao. Department of Anesthesiology, Sun Yet-sen Memorial Hospital, Sun Yet-sen University, Guangzhou \\ 510000, China. Email: jift@mail.sysu.edu.cn; caomh@mail.sysu.edu.cn.
}

\begin{abstract}
Abnormal tracheal bronchus originates from the sidewall of the trachea, and most frequently occurs on the right side, involves subsegmental bronchi and the segmental. The anatomical structure of the airway is of great significance for general anesthesia and lung isolation. Abnormal tracheal bronchus makes lung isolation more complicated. This study presents four rare cases of aberrant tracheobronchial anatomy in the right main bronchus. We review the literature and discuss our solution and propose possible solutions for lung isolation in patients with tracheobronchial abnormalities. Of these, three patients were scheduled for radical resection of lung cancer, and one patient was scheduled for radical resection of middle esophageal cancer. After anesthesia induction, we intubated the right-side double-lumen tube (DLT) using a fiberoptic bronchoscope to guide the intubation. During DLT repositioning, we discovered the tracheobronchial abnormality of the patients. We could not place the DLT appropriately, however we made an effort to achieve lung isolation. We used a bronchus blocker [(BB) Univent tube] to achieve lung isolation for case 1, and the patient had good ventilation and no dyspnea and carbon dioxide retention during the operation. We completed lung isolation for the other three patients with abnormal airways by adjusting the position and replacing the DLT.
\end{abstract}

Keywords: Double-lumen endotracheal tube; bronchus blocker (BB); aberrant tracheal anatomy; lung isolation; case report

Submitted May 25, 2021. Accepted for publication Aug 06, 2021.

doi: $10.21037 /$ atm-21-3535

View this article at: https://dx.doi.org/10.21037/atm-21-3535

\section{Introduction}

At present, the incidence of congenital airway abnormalities is approximately $0.1-2 \%(1)$. Although some patients who have airway abnormalities may experience recurrent pneumonia, chronic bronchitis, or bronchiectasis, most cases of the tracheobronchial disease are asymptomatic (2). Although there have been some case reports on abnormal tracheal bronchus before, there were usually only one case in these reports, and there are no reports of treatment and typing differences between different abnormal tracheal bronchus cases. In this study, placement of the doublelumen tube (DLT) in four patients with abnormal right bronchus undergoing radical surgery for lung cancer failed at the first attempt. Finally, a bronchial blocker (BB) was used to successfully ventilate the patients. We also reviewed the anesthesia records of three patients with aberrant tracheal anatomy. We present the following article in accordance with the CARE reporting checklist (available at https://dx.doi.org/10.21037/atm-21-3535).

\section{Case presentation}

\section{Case 1}

Case 1 involves a 58-year-old male patient who underwent thoracoscopic radical resection of lung cancer. A preoperative chest CT (computed tomography) is shown in 


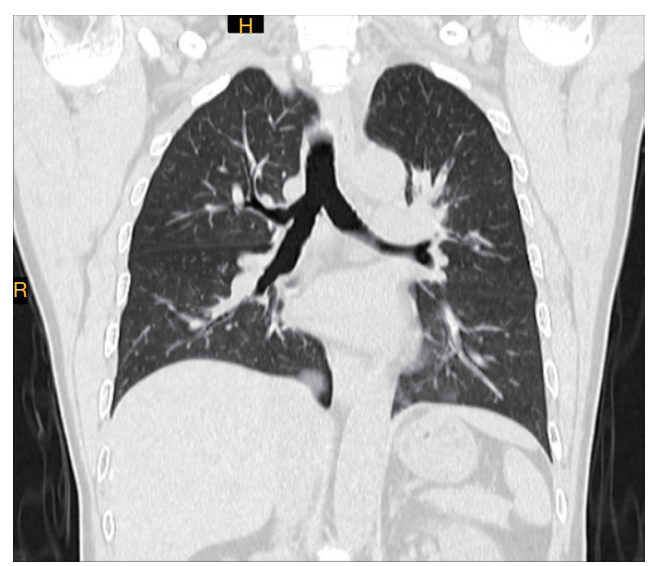

Figure 1 Preoperative chest radiograph.

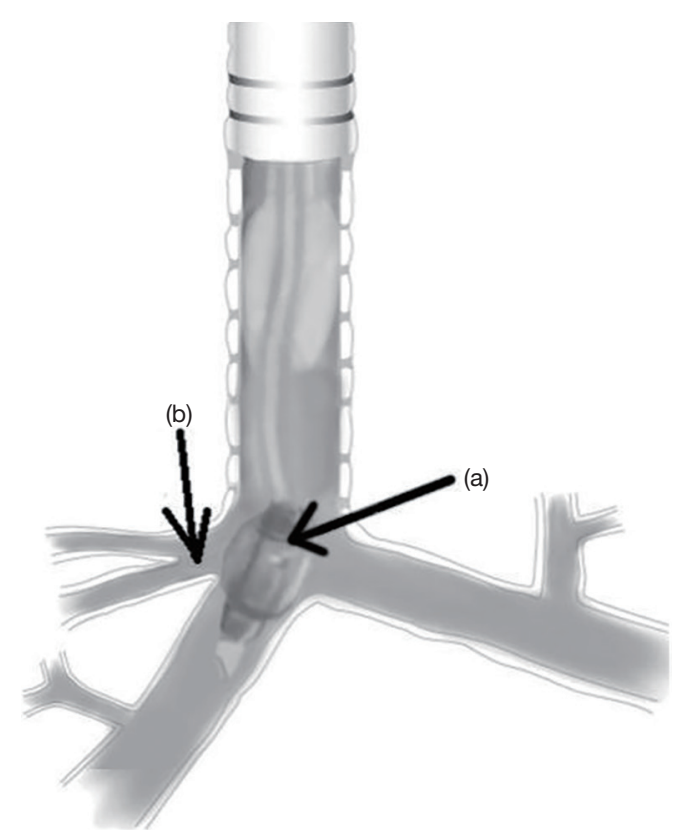

Figure 2 Schematic rendering of a 37 right double-lumen tube (DLT) located in the right mainstem bronchus: (a) the blue cuff is stuck in the right trachea (half of which is in the main trachea and cannot be entered); (b) it is blocking the right upper lung opening; it is not ventilating.

Figure 1. The ASA (American Society of Anesthesiologists) standard monitor was preoperatively placed for the patient. He was induced with sufentanil, propofol, and cis-atracurium for intravenous general anesthesia. The right bronchial tube was placed blindly, and its location was confirmed by flexible fiberoptic bronchoscopy (FOB). We scrutinized the tracheobronchial anatomy, which

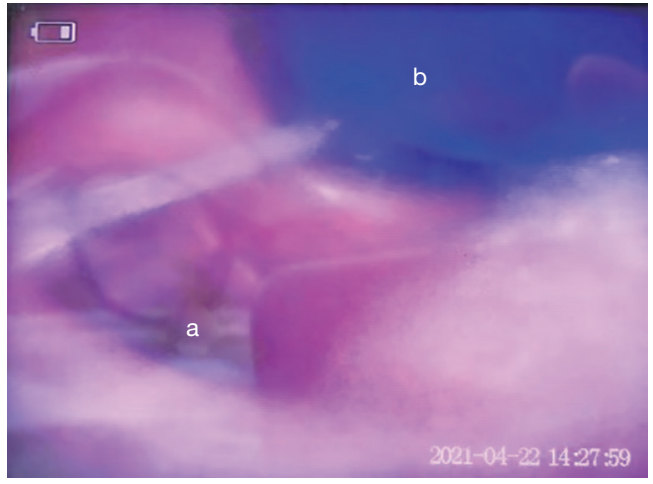

Figure 3 Bronchoscopic view of the tracheal bronchus. (a) left mainstem bronchus; (b) right mainstem bronchus.

showed that the DLT was deeply inserted into the right middle and lower bronchus, but could not enter the right bronchus entirely. Half of the blue cuff was exposed outside. We unsuccessfully tried to enter $1-2 \mathrm{~cm}$ by inserting an exchange tube. The DLT and FOB were then pulled up along the trachea until the carina was developed and the airway abnormality was found. We identified three outlets in the carina, which were similar to the tracheal trifurcation (Figure 2). The bronchoscopy clearly showed the location of the right trachea and the presence of abnormal tracheal bronchus. Despite multiple maneuvers, we were unable to obtain sufficient volumes. The abnormal pulmonary bronchus blocked the lumen of the DLT (Figure 3), despite changing to another DLT 37R. After discussion with the surgical group, we decided to use a BB. After successfully intubating the standard catheter under direct laryngoscopy, we pushed the blocked catheter into the left main bronchus with bronchoscopy guidance. The balloon was then blocked in the left bronchus and inflated 4-8 mL. After confirming that there was no leakage, we checked that it was $0.5-1 \mathrm{~cm}$ below the left bronchus opening (Figure 4).

\section{Other cases}

We also reviewed our experiences with the three remaining patients, which are described in Figure 5 and Table 1. These patients were intubated twice. In case 2 and case 4, the opening position was adjusted via intraoperative fiberoptic bronchoscope guidance, and the ventilation level was barely reached, but the effect of pulmonary ventilation was unsatisfying. In case 4 , the right DLT was not adjusted to a satisfactory ventilation level, and the left DLT was replaced after consultation with the surgeon. Cases 2 and 4 were type 


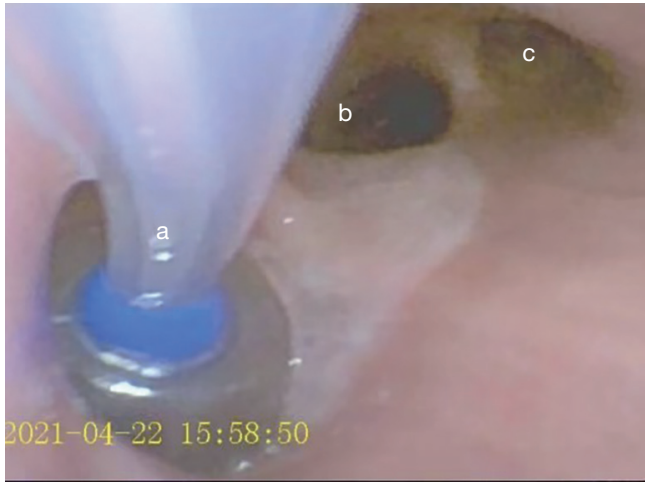

Figure 4 Bronchoscopic view of a bronchial blocker (blue cuff) located in the left main stem bronchus. (a) Bronchial blocker; (b) right lower bronchus; (c) right upper bronchus.
C, and case 3 was type A, according to the types of tracheal bronchus described by Conacher (3).

\section{Ethical Statement}

All procedures performed in studies involving human participants were in accordance with the ethical standards of the national research committee and with the Helsinki Declaration (as revised in 2013). Written informed consent was obtained from the patient for publication of this manuscript and any accompanying images. A copy of the written consent is available for review by the editorial office of this journal.
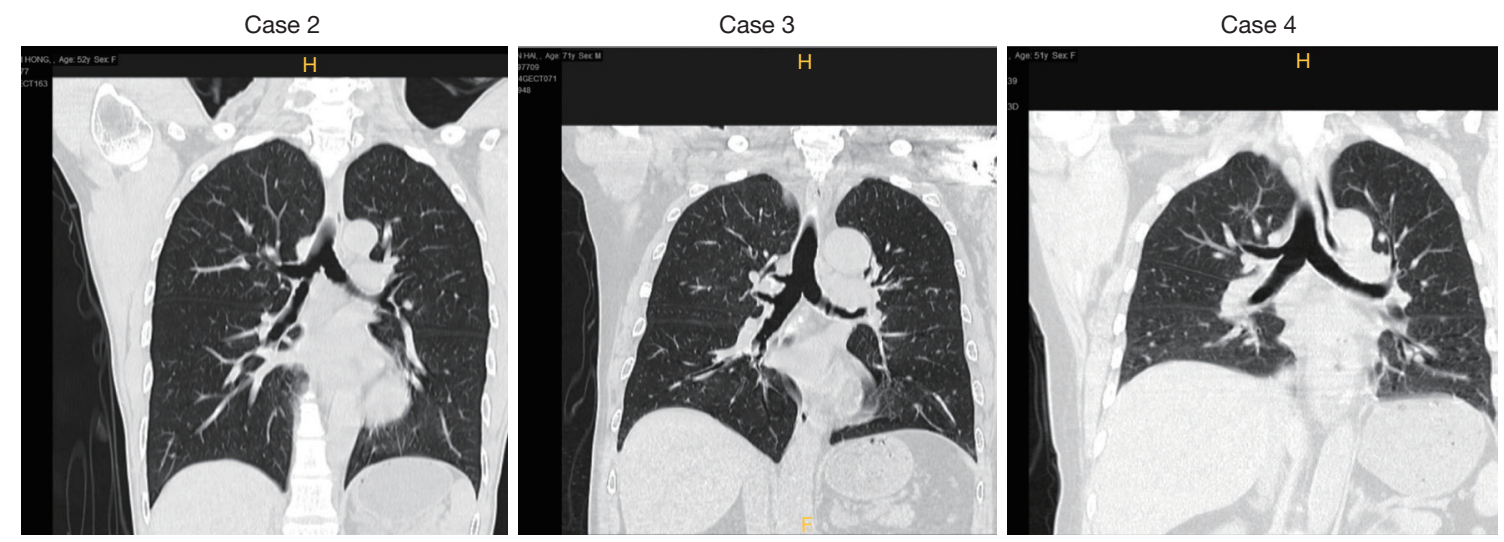

Figure 5 Preoperative chest radiograph of case 2, case 3 and case 4 .

Table 1 Patient characteristics

\begin{tabular}{|c|c|c|c|c|c|c|c|}
\hline Patient & Procedure, age/gender & Height/weight & $\begin{array}{c}\text { Mallampati } \\
\text { score }\end{array}$ & $\begin{array}{c}\text { Airway } \\
\text { features (3) }\end{array}$ & DLT type & $\begin{array}{l}\text { Success/ } \\
\text { attempts }\end{array}$ & BB \\
\hline 1 & Thoracoscopy, 65/M & $164 \mathrm{~cm} / 62 \mathrm{~kg}$ & II & C & 35 Fr right fail & $\mathrm{No} / 2$ & Yes \\
\hline 2 & Thoracoscopy, 52/F & $155 \mathrm{~cm} / 61 \mathrm{~kg}$ & II & $\mathrm{C}$ & 35 Fr left & Yes/2 & No \\
\hline 3 & Radical operation of left upper lung cancer & & & & & & \\
\hline \multirow[t]{2}{*}{4} & Thoracoscopy, 52/F & $155 \mathrm{~cm} / 44 \mathrm{~kg}$ & II & $\mathrm{C}$ & 35 Fr right fail & Yes/2 & No \\
\hline & Radical operation of left upper lung cancer & & & & 35 Fr left & & \\
\hline
\end{tabular}

M, male; F, female; Fr, French, DLT, double-lumen tube; BB, bronchial blocker. 


\section{Discussion}

Abnormal tracheal bronchusoriginates from the sidewall of the trachea, which is located above the carina (4). It almost occurs on the right side and usually represents the origin of the displacement of the right main bronchus or the apical segmental bronchus (5). Conacher et al. described the subtypes of tracheal bronchus, in which type A was $\geq 2 \mathrm{~cm}$ above carina with distal tracheal stenosis, type $B$ was $\geq 2 \mathrm{~cm}$ above carina and distal tracheal diameter was normal, and type $\mathrm{C}$ was $\leq 2 \mathrm{~cm}$ above carina (3). For the tracheobronchial cases requiring airway management, pulmonary isolation was also challenging or inadequate for the anesthesiologists. We carefully reviewed the CT scan of the chest after intubation and found that the left, right upper, and right lower tube opening was in the same plane. Finally, we chose tracheobronchial occlusion. The balloon was measured before placement, and the position was appropriate. If we had known about this problem before the operation, we could have employed bronchial occlusion at the beginning. With the progress of science and technology, we can use bronchial occlusion at the beginning; with artificial intelligence recognition chest X-ray CT results and the integration of big data, we hope to be able to preoperatively predict the risk of airway abnormalities at some point.

Previous studies have shown that BBs can achieve the same satisfactory effect of one-lung ventilation and satisfactory lung collapse as a double lumen catheter (6). Campos et al. believed that the BB was more likely to shift from the supine position to the lateral position than the left DLT, while the incidence of displacement was similar compared with a right DLT. They believe that before changing the position, the gas should be drawn out to plug the cuff and reinflated after placing the position, thereby reducing the displacement of the catheter plug (7). Since the cavity of the occluder is small, the gas in the lung is not easily discharged, so continuous negative pressure suction is needed. Baraka et al. highlighted that negative pressure suction on the non-ventilated side should be performed at least after thoracotomy; otherwise, it may lead to severe hypoxemia (8). Continuous negative pressure suction on the non-ventilated side may cause severe negative pressure pulmonary edema. Therefore, it would be an excellent choice to suspend mechanical ventilation, deflate the intubation cuff, ventilate the endotracheal tube to induce lung collapse, and subsequently start the intubation cuff again to implement mechanical ventilation. Of course, there are also some problems associated with the use of the Univent catheter. The most common problem is that the lumen of the inner cannula is too thin, and it cannot be quickly and effectively attracted when there are more secretions or bleeding. In addition, when the inner wall of the catheter is torn, the bronchial stamp closure device is cut off to block the catheter. The accidental inflation of the blocking cuff during postoperative mechanical ventilation results in severe respiratory disorders (9), and the insertion of the blocking tube too deep may cause airway injury and even severe tension pneumothorax tracheal perforation.

The patient-specific and surgical factors are essential considerations in the process of implementing lung isolation technology. Difficult airways and children's airways remain challenging for the implementation of lung isolation technology. Preoperatively, anesthesiologists need to inquire about the history and CT films, especially the results of tracheostomy, to understand the shape of the protrusion and the inner diameter of the bronchus. Finally, it is also crucial to keep records before tracheal intubation.

\section{Acknowledgments}

Funding: This work was supported by the Guangdong Natural Science Foundation Program of China (grant 2021A1515012357 to YL).

\section{Footnote}

Reporting Checklist: The authors have completed the CARE reporting checklist. Available at https://dx.doi. org/10.21037/atm-21-3535

Conflicts of Interest: All authors have completed the ICMJE uniform disclosure form (available at https://dx.doi. org/10.21037/atm-21-3535). The authors have no conflicts of interest to declare.

Ethical Statement: The authors are accountable for all aspects of the work in ensuring that questions related to the accuracy or integrity of any part of the work are appropriately investigated and resolved. All procedures performed in studies involving human participants were in accordance with the ethical standards of the national research committee and with the Helsinki Declaration (as revised in 2013). Written informed consent was obtained from the patient for publication of this manuscript and any accompanying images. A copy of the written consent is available for review by the editorial office of this journal. 
Open Access Statement: This is an Open Access article distributed in accordance with the Creative Commons Attribution-NonCommercial-NoDerivs 4.0 International License (CC BY-NC-ND 4.0), which permits the noncommercial replication and distribution of the article with the strict proviso that no changes or edits are made and the original work is properly cited (including links to both the formal publication through the relevant DOI and the license). See: https://creativecommons.org/licenses/by-nc-nd/4.0/.

\section{References}

1. Wiser SH, Hartigan PM. Challenging lung isolation secondary to aberrant tracheobronchial anatomy. Anesth Analg 2011;112:688-92.

2. Lee HL, Ho AC, Cheng RK, et al. Successful one-lung ventilation in a patient with aberrant tracheal bronchus. Anesth Analg 2002;95:492-3, table of contents.

3. Conacher ID. Implications of a tracheal bronchus for adult anaesthetic practice. Br J Anaesth 2000;85:317-20.

4. Okubo K, Ueno Y, Isobe J. Upper sleeve lobectomy for

Cite this article as: Lu Y, Xu D, Liu Z, Liu T, Zeng J, Cao M, Ji F. The use of bronchial blockers in patients with aberrant tracheobronchial anatomy: a case report. Ann Transl Med 2021;9(15):1268. doi: 10.21037/atm-21-3535 lung cancer with tracheal bronchus. J Thorac Cardiovasc Surg 2000;120:1011-2.

5. Read R, St Cyr J, Marek J, et al. Bronchial anomaly of the right upper lobe. Ann Thorac Surg 1990;50:980-1.

6. Campos JH, Kernstine KH. A comparison of a left-sided Broncho-Cath with the torque control blocker univent and the wire-guided blocker. Anesth Analg 2003;96:283-9, table of contents.

7. Campos JH, Reasoner DK, Moyers JR. Comparison of a modified double-lumen endotracheal tube with a singlelumen tube with enclosed bronchial blocker. Anesth Analg 1996;83:1268-72.

8. Campos JH. An update on bronchial blockers during lung separation techniques in adults. Anesth Analg 2003;97:1266-74.

9. Dougherty P, Hannallah M. A potentially serious complication that resulted from improper use of the Univent tube. Anesthesiology 1992;77:835.

(English Language Editor: A. Kassem) 